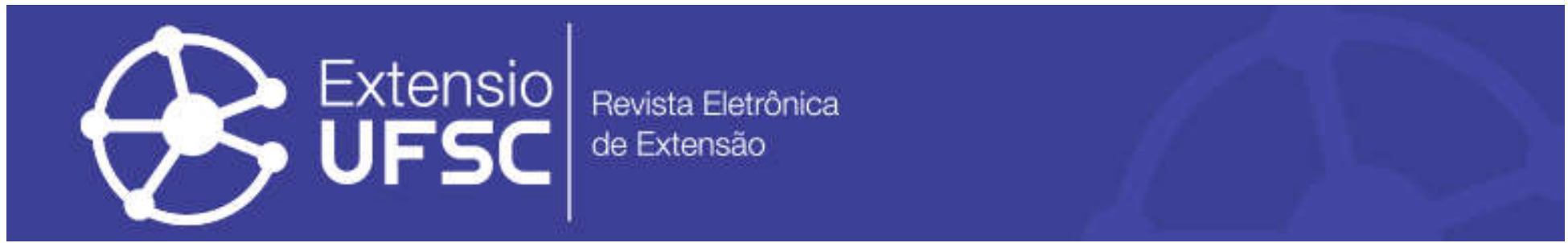

\title{
FOTOLIVRE360, RELATO DE UMA EXPERIÊNCIA INOVADORA
}

\author{
Flávia Garcia Guidotti \\ Universidade Federal de Santa Catarina \\ flaviaguidotti@hotmail.com \\ Raquel Ritter Longhi \\ Universidade Federal de Santa Catarina \\ raqlonghi@gmail.com
}

\author{
Lívia Tokasiki \\ Universidade Federal de Santa Catarina \\ liviatok@gmail.com \\ Luiz Felipe Buzzi \\ Universidade Federal de Santa Catarina \\ lfelipebuzzi@hotmail.com
}

\section{Resumo}

O Projeto de Extensão Fotolivre360 foi criado para democratizar o acesso às diferentes técnicas de registro fotográfico digital (com smartphones, DSLR, câmeras esportivas e com câmeras para a produção de fotografias $360^{\circ}$ ). Durante o ano de 2018, foram realizadas 14oficinas com jovens estudantes universitários e com adolescentes de regiões periféricas de Florianópolis, divulgadas nas redes sociais Facebook e Instagram. O projeto superou as expectativas iniciais, uma vez que conseguiu agregar a comunidade acadêmica e a comunidade em geral, funcionando não apenas como vetor de instruções técnicas, mas também como meio de reflexão acerca dos registros realizados, possibilitando a esses estudantes agirem como sujeitos de suas próprias histórias e de suas próprias imagens.

Palavras-chave: Jornalismo. Fotojornalismo. Fotografia Digital. Fotografia $360^{\circ}$.

\section{FOTOLIVRE360, AN INNOVATIVE EXPERIENCE REPORT}

\begin{abstract}
The Fotolivre360 Extension Project was created to democratize access to different digital photographic recording techniques (with smartphones, DSLR, sports cameras and cameras for producing $360^{\circ}$ photographs). During 2018, 14 workshops were held with young university students and teenagers from the poor region of Florianópolis, published on the social networks Facebook and Instagram. The project exceeded its initial expectations, since it was able to aggregate the academic community and the community in general, working not only as a vector of technical instructions, but also as a means of reflection on the records made, enabling these students to act as subjects of their own stories and their own images.
\end{abstract}

Key-words: Journalism. Photojournalism. Digital Photography. $360^{\circ}$ Photography.

\section{FOTOLIVRE360, UN RELATO DE EXPERIENCIA INNOVADORA}

\begin{abstract}
Resumen
El proyecto de extensión Fotolivre360 fuecreado para democratizar elacceso a diferentes técnicas de grabación fotográfica digital (conteléfonos inteligentes, DSLR, cámarasdeportivas y cámaras para producirfotografías de $360^{\circ}$ ). Durante 2018 , se realizaron 14talleresconjóvenesuniversitarios y adolescentes de laregión pobre de Florianópolis, publicados enlas redes socialesFacebook e Instagram. El proyectosuperósus expectativas iniciales, ya que fue capaz de agregar a lacomunidad académica y a lacomunidaden general, trabajando no solo como un vector de instrucciones técnicas, sino también como unmedio de reflexión sobre los registros realizados, permitiendo a estosestudiantesactuar como sujetosdesuspropiashistorias y de sus propias imágenes.
\end{abstract}

Palabras-clave: Periodismo. Fotoperiodismo. Fotografía Digital. Fotografía 360 grados. 


\section{INTRODUÇÃO}

Este artigo tem o objetivo de relatar a experiência do Projeto de Extensão Fotolivre360 no ano de 2018. Surgido a partir do Projeto de Extensão Fotolivre.ufsc, lançado no ano de $2009^{1}$, o Fotolivre360 vem sendo desenvolvido desde 2017, quando se deu a primeira oficina de Jornalismo Imersivo, na $16^{\text {a }}$ Sepex - Semana de Ensino, Pesquisa e extensão da UFSC. A mesma foi oferecida pela coordenadora do projeto, Professora Raquel Ritter Longhi, e pelo Grupo Hipermídia e Linguagem/CNPq e Nephi-Jor/UFSC, acompanhando o desenvolvimento de novas tecnologias de produção de imagens, especialmente as de captação em 360 graus, também conhecidas como imagens esféricas.

Durante o ano de 2018, o Projeto Fotolivre360 teve como principal objetivo divulgar a tecnologia da captação de imagens 360 graus entre a comunidade universitária e a comunidade em geral, através de oficinas direcionadas a estudantes de graduação da UFSC e de outras Universidades e a comunidades periféricas de Florianópolis, além de fornecer subsídios teóricos e práticos para que adolescentes de classes populares pudessem se expressar através da produção e distribuição de imagens fotográficas.

De março a outubro de 2018, quando o projeto contou com dois bolsistas do Programa Probolsas, Lívia Tokasiki e Luís Felipe Buzzi, sob a coordenação das professoras Raquel Ritter Longhi e Flávia Garcia Guidotti, foram realizadas 14 oficinas, que tiveram entre quatro e oito horas de duração.

Como preparação para as oficinas que seriam realizadas, fizemos uma apresentação do projeto e um treinamento com alunos da Graduaçãoe da Pós-Graduação emJornalismo da UFSC, com o objetivo de formar um grupo de voluntários para atuar nas atividades que seriam desenvolvidas. Depois disso, passamos às atividades que aconteceram conforme o quadro abaixo.

\footnotetext{
1 Ao longo desse período, o Fotolivre contou com duas configurações diferentes. As primeiras edições tinham o objetivo de constituir um banco de imagens digitais com as melhores fotografias realizadas pelos alunos das disciplinas de Fotojornalismo do Curso de Jornalismo da UFSC. As imagens digitais eram selecionadas pelas professoras e pelos bolsistas do projeto e eram disponibilizadas gratuitamente no site Fotolivre.ufsc, sob licença livre Creative Commons. Essa primeira configuração foi muito importante para dar visibilidade aos trabalhos dos alunos do curso de Jornalismo da UFSC, bem como atendeu satisfatoriamente a muitos usuários que utilizaram essas imagens para ilustrar blogs, sites, livros, revistas e até propagandas.
} 
Quadro 1: Síntese das oficinas realizadas durante o Projeto Fotolivre360

\begin{tabular}{|c|c|c|}
\hline $\begin{array}{l}\mathrm{N}^{\mathbf{o}} \text { de } \\
\text { oficinas } \\
\text { realizadas }\end{array}$ & Local da oficina & Cidade \\
\hline 2 & Casa da Criança do Morro da Penitenciária & Florianópolis, SC \\
\hline 1 & Comunidade do Siri, no bairro Ingleses & Florianópolis, SC \\
\hline 2 & $\begin{array}{l}\text { Centro Educacional Marista Lucia Mayvorne, no Morro da } \\
\text { Serrinha }\end{array}$ & Florianópolis, SC \\
\hline 1 & $\begin{array}{l}\text { Disciplina Estudos de Gênero e Formatos Jornalísticos do } \\
\text { Programa de Pós-Graduação em Jornalismo da UFSC }\end{array}$ & Florianópolis, SC \\
\hline 3 & $\begin{array}{l}\text { Disciplina Laboratório de Fotojornalismo do Curso de } \\
\text { Jornalismo da UFSC, sendo uma delas realizada durante a } \\
\text { saída de estudos junto à Fortaleza de São José da Ponta } \\
\text { Grossa }\end{array}$ & Florianópolis, SC \\
\hline 1 & $\begin{array}{l}\text { I Encontro Norte e Nordeste da ABCiber (Associação } \\
\text { Brasileira de Pesquisadores em Ciberjornalismo) }\end{array}$ & São Luís - MA \\
\hline 1 & $\begin{array}{l}41^{\circ} \text { Intercom. Congresso Brasileiro de Ciências da } \\
\text { Comunicação, realizado na Univille (Universidade da Região } \\
\text { de Joinville) }\end{array}$ & Joinville, SC \\
\hline 1 & $\begin{array}{l}1^{a} J I J \text { (Jornada de Inovação no Jornalismo), realizada na } \\
\text { UFSC }\end{array}$ & Florianópolis, SC \\
\hline 1 & $\begin{array}{l}17^{a} \text { Sepex (Semana de Ensino, Pesquisa, Extensão e Inovação) } \\
\text { da UFSC }\end{array}$ & Florianópolis, SC \\
\hline 1 & IFSC Campus Pedra Branca & Palhoça, SC \\
\hline
\end{tabular}

Os resultados das oficinas foram publicados em perfis nas redes sociais Facebook (@fotolivreufsc360) e Instagram (@fotolivre360) e atingiram um público crescente a cada postagem, tendo, no final de 2018, contado com aproximadamente 1,2 mil visualizações orgânicas em cada post. Vitrines do projeto, os perfis nas redes sociais funcionaram como ponto de confluência das atividades específicas de extensão, servindo para a divulgação das oficinas de produção de imagens em 360 graus e também como uma plataforma de divulgação da produção gerada e de atividades do Projeto de Pesquisa Narrativas Imersivas no Ciberjornalismo: Estudo e Aplicabilidade ${ }^{2}$.

Nesse sentido, o Projeto Fotolivre360 foi uma atividade de extensão que manteve um estreito diálogo com a pesquisa e com o ensino, tentando sempre atender às demandas da indissociabilidade entre os três pilares da universidade pública - ensino, pesquisa e extensão.

\footnotetext{
2 Projeto de pesquisa coordenado pela Professora Raquel Ritter Longhi que integra ainda as atividades de extensão do Fotolivre360.
} 
Neste artigo apresentamos o relato detalhado de três oficinas realizadas, ao mesmo tempo em que refletimos sobre os seus efeitos nos sujeitos participantes.

\section{REFERENCIAL TEÓRICO}

A fotografia de cunho social tem sido um dos principais temas das grandes reportagens fotográficas e do documentarismo fotográfico. Talvez pela fotografia se constituir em uma linguagem universal, capaz de ultrapassar fronteiras linguísticas, muitos jornalistas e documentaristas têm confiado no seu potencial para registrar e perpetuar diferentes sociedades e culturas.

A importância da fotografia documental tem sido reconhecida por historiadores, sociólogos, antropólogos, entre outros, que veem nela uma potente ferramenta para seus estudos e também um poderoso instrumento de denúncia social e de modificação das realidades. Para Sousa (2004), "o sucesso desse modelo se deu graças ao enorme desejo de conhecer o outro, de saber como ele vive, o que pensa, como vê o mundo e com o que se importa. As palavras são insuficientes" (p. 55). Para o pesquisador Paulo César Boni, o triunfo da fotografia documental está atrelado ao fato de que "em razão da veemência do imagético, ela gera maior impacto que outros meios" (BONI, 2008, p. 3).

Mais recentemente, porém, alguns pesquisadores começaram a questionar a forma como esses registros das sociedades e culturas têm sido feitos ao longo dos anos, como é o caso de Forin Jr. e Boni (2007), que alertam para a forma caricatural e exótica como muitas vezes são apresentados os excluídos sociais, aumentando ainda mais o abismo social existente entre as classes.

A partir dessas constatações, é possível perceber a importância de que os próprios moradores das comunidades realizem seus registros fotográficos, em vez de serem fotografados por pessoas que não pertençam às comunidades.

O antropólogo Milton Guran é outro autor que alerta para o risco de delegar a outrem a produção de sua própria imagem. Ele afirma que "uma sociedade ou um grupo social quando abre mão de produzir a sua própria imagem está renunciando a si mesmo, e assim, começa a deixar de existir enquanto sociedade ou grupo social distinto" (GURAN, 2008, p. 109).

Essas novas imagens, produzidas por sujeitos comuns transformados em fotógrafos cidadãos, trazem um olhar renovado ao fotodocumentarismo, com produtos compostos de muitas subjetividades e vozes polifônicas, com o poder de desalienar suas próprias imagens. Assim foram as imagens produzidas pelos grupos participantes das oficinas. 
Outro aspecto que mereceu nossa atenção durante o projetofoi o acesso às tecnologias fotográficas. Em tempos de vertiginosa velocidade no desenvolvimento das tecnologias, de ampliação das facilidades de acesso à Internet, de ampla inserção de telefones celulares, que permitem tanto o acesso à Rede de Computadores como a agilidade na produção de conteúdos compartilháveis, e num momento onde o Jornalismo desenvolve-se buscando acompanhar a tecnologia, é fundamental também preocupar-se com a ampliação do acesso a essas inovações. As comunidades periféricas, hoje em dia, têm acesso a telefones celulares e à Internet, mas seu uso está restrito a poucas atividades, se pensarmos na potencialidade da tecnologia para a produção de conteúdos, tanto aqueles do nosso diaadia, como aqueles que poderão ser compartilhados em sociedade. O surgimento da tecnologia de captação de imagens em 360 graus, com a facilitação da produção de imagens estáticas (fotografias) e em movimento (vídeos) em 360 graus, ainda é algo que marca um fosso entre as classes mais favorecidas, que podem ter acesso a tais ferramentas, e as menos favorecidas, que mal conhecem esse tipo de tecnologia.

Levar esse tipo de tecnologia às populações periféricas, colaborando para que possa ser usada como ferramenta de comunicação nas comunidades, ao mesmo tempo em que se acompanha o desenrolar destes novos tipos de imagens e sensibilidades, foi uma atribuição importante e fundamental da proposta. Entendemos que nosso trabalho como professoras e pesquisadoras será enriquecido pela perspectiva da extensão no que diz respeito à inclusão social a partir de um trabalho em comunidade, por isso a importância do Fotolivre360.

As oficinas realizadas nas comunidades tiveram dois momentos distintos: no primeiro, os participantes foram apresentados a diversos tipos de tecnologia de captação de imagens para posteriormente serem instigados a produzirem suas próprias imagens, de acordo com as características próprias de suas comunidades e com foco em questões sociais.

\section{MATERIAIS E MÉTODOS}

A primeira atividade do projeto Fotolivre360 foi a realização de uma oficina com os alunos da Graduação e da Pós-Graduação em Jornalismo da Universidade Federal de Santa Catarina. Essa oficina inicial teve como objetivo a apresentação do projeto e a formação de equipes para a realização das oficinas nas comunidades.

Simultaneamente à organização da primeira oficina, começamos os contatos com as associações comunitárias de comunidades periféricasda cidade de Florianópolis, explicando como seria realizado o projeto e pedindo indicações de onde e quando realizar as atividades nas comunidades. 
Depois da definição dos locais e do cronograma de oficinas que faríamos durante o ano, começamos a preparação das mesmas com a elaboração de materiais didáticos e com a montagem da equipe que atuaria em cada um dos locais. Essa etapa foi realizada nas dependências do Curso de Jornalismo da UFSC e contou com a presença das coordenadoras do projeto, dos dois bolsistas Probolsas e de acadêmicos da Graduação em Jornalismo e do Programa de Pós-Graduação em Jornalismo da UFSC. Neste momento também criamos os perfis nas redes sociais Facebook (@fotolivreufsc360) e Instagram (@fotolivre360), que serviram para a divulgação das atividades e, principalmente, para a postagem das imagens obtidas nas oficinas e saídas fotográficas feitas nas comunidades periféricas.

A sistemática de organização das oficinas deu-se da seguinte forma: os bolsistas ficaram responsáveis por fazer um levantamento de comunidades da região que poderiam estar dispostas a participar do projeto, e as coordenadoras fizeram o primeiro contato com as instituições que demonstraram interesse. Feito isso, as oficinas eram pensadas previamente em reuniões entre coordenadoras, bolsistas e voluntários.

As oficinas foram ministradas nas próprias comunidades e contaram com equipamentos próprios das professoras coordenadoras e também com os equipamentos excedentes pertencentes ao Laboratório de Fotojornalismo curso de Jornalismo da UFSC.

Por se tratar de uma tecnologia nova e não muito acessível no mercado, decidimos que as primeiras oficinas do Fotolivre não se limitariam apenas à fotografia em 360. Além de divulgar a tecnologia, uma de nossas principais preocupações era se de fato as oficinas poderiam ter algum resultado transformador na vida dos participantes, fossem eles crianças, adolescentes ou adultos. O foco era a inclusão, por isso, pensamos que no primeiro encontro com as comunidades seria mais interessante apresentarmos a eles um contexto básico e geral sobre a fotografia e o fotojornalismo. O 360 e a Realidade Virtual seriam apresentados num segundo momento, onde eles já estariam familiarizados com o projeto e com a fotografia.

Sendo assim, no primeiro encontro foram apresentados diferentes equipamentos de captação fotográfica e introduzimos conceitos básicos da linguagem fotográfica, bem como algumas regras compositivas. Entendemos que essa noção básica sobre linguagem e estética seria muito importante não só para que os jovens pudessem produzir melhores imagens durante o projeto, mas também depois, com a utilização de equipamentos próprios, como as câmeras de celulares que a maioria deles possuía. Nesse momento trouxemos muitos exemplos, sempre tentando dialogar com os produtos culturais consumidos por aqueles jovens, como imagens de rappers, funkeiros, entre outros; e também trouxemos imagens de projetos desenvolvidos em comunidades com características semelhantes àquelas, essas últimas com um foco mais social. 
No segundo encontro, partíamos para a prática, instigando os jovens a saírem com os equipamentos e fotografarem os seus entornos.

Como uma espécie de encerramento do encontro fazíamos a publicação dos registros nas redes sociais. Esta etapa era feita pelos bolsistas, com a supervisão das coordenadoras e era realizada logo após as oficinas.

\section{RESULTADOS E ANÁLISES}

Ao todo, foram realizadas 14 oficinas: cinco em comunidades periféricas;e nove abrangendo o Departamento de Jornalismo, a Comunidade da UFSC, a Comunidade externa à UFSC e universidades de outras cidades e estados, como podemos ver no quadro abaixo:

Quadro 2: Detalhamento das oficinas realizadas durante o Projeto Fotolivre360

\begin{tabular}{|c|c|c|c|c|c|}
\hline Data & Instituição/Evento & Local & Público alvo & $\begin{array}{l}\text { Faixa } \\
\text { etária }\end{array}$ & $\begin{array}{l}\mathbf{N}^{\circ} \text { de } \\
\text { particip. }\end{array}$ \\
\hline $22 / 04$ & $\begin{array}{l}\text { Disciplina Estudos de } \\
\text { Gênero e Formatos } \\
\text { Jornalísticos do } \\
\text { Programa de Pós- } \\
\text { Graduação em } \\
\text { Jornalismo da UFSC }\end{array}$ & $\begin{array}{l}\text { Florianópolis, } \\
\text { SC }\end{array}$ & $\begin{array}{l}\text { Alunos de } \\
\text { Mestrado e } \\
\text { Doutorado }\end{array}$ & $22-30$ & 09 \\
\hline $07 / 05$ & $\begin{array}{l}\text { Casa da Criança Morro } \\
\text { da Penitenciária }\end{array}$ & $\begin{array}{l}\text { Florianópolis, } \\
\text { SC }\end{array}$ & $\begin{array}{l}\text { Crianças da } \\
\text { comunidade }\end{array}$ & $7-12$ & 15 \\
\hline $14 / 05$ & $\begin{array}{l}\text { Casa da Criança Morro } \\
\text { da Penitenciária }\end{array}$ & $\begin{array}{l}\text { Florianópolis, } \\
\text { SC }\end{array}$ & $\begin{array}{l}\text { Adolescentes da } \\
\text { comunidade }\end{array}$ & $13-16$ & 20 \\
\hline $22 / 05$ & $\begin{array}{l}\text { Saída de estudos junto à } \\
\text { Fortaleza de São José da } \\
\text { Ponta Grossa }\end{array}$ & $\begin{array}{l}\text { Florianópolis, } \\
\text { SC }\end{array}$ & $\begin{array}{l}\text { Alunos do Curso } \\
\text { de Jornalismo da } \\
\text { UFSC }\end{array}$ & $18-22$ & 35 \\
\hline $14 / 06$ & $\begin{array}{l}\text { I Encontro Norte e } \\
\text { Nordeste da ABCiber } \\
\text { (Associação Brasileira de } \\
\text { Pesquisadores em } \\
\text { Ciberjornalismo) }\end{array}$ & São Luís, MA & $\begin{array}{l}\text { Alunos do Curso } \\
\text { de Comunicação } \\
\text { Social da } \\
\text { Universidade } \\
\text { Federal do } \\
\text { Maranhão }\end{array}$ & $18-22$ & 12 \\
\hline $24 / 06$ & $\begin{array}{l}\text { Comunidade do Siri, no } \\
\text { Bairro dos Ingleses }\end{array}$ & $\begin{array}{l}\text { Florianópolis, } \\
\text { SC }\end{array}$ & $\begin{array}{l}\text { Crianças da } \\
\text { comunidade }\end{array}$ & $7-12$ & 15 \\
\hline $\begin{array}{l}21 / 08 \\
\text { (manhã) }\end{array}$ & $\begin{array}{l}\text { Disciplina Laboratório } \\
\text { de Fotojornalismo, } \\
\text { UFSC }\end{array}$ & $\begin{array}{l}\text { Florianópolis, } \\
\text { SC }\end{array}$ & $\begin{array}{l}\text { Alunos do Curso } \\
\text { de Jornalismo da } \\
\text { UFSC }\end{array}$ & $18-22$ & 15 \\
\hline
\end{tabular}




\begin{tabular}{|c|c|c|c|c|c|}
\hline $\begin{array}{l}21 / 08 \\
\text { (tarde) }\end{array}$ & $\begin{array}{l}\text { Disciplina Laboratório } \\
\text { de Fotojornalismo, } \\
\text { UFSC }\end{array}$ & $\begin{array}{l}\text { Florianópolis, } \\
\text { SC }\end{array}$ & $\begin{array}{l}\text { Alunos do Curso } \\
\text { de Jornalismo da } \\
\text { UFSC }\end{array}$ & $18-22$ & 15 \\
\hline 08/09 & $\begin{array}{l}41^{\circ} \text { Intercom. Congresso } \\
\text { Brasileiro de Ciências da } \\
\text { Comunicação, realizado } \\
\text { na Univille } \\
\text { (Universidade da Região } \\
\text { de Joinville) }\end{array}$ & Joinville, SC & $\begin{array}{l}\text { Estudantes de } \\
\text { diversos cursos de } \\
\text { comunicação do } \\
\text { Brasil }\end{array}$ & $18-25$ & 15 \\
\hline $18 / 10$ & $\begin{array}{l}1^{\text {a }} \text { JIJ (Jornada de } \\
\text { Inovação no } \\
\text { Jornalismo), realizada na } \\
\text { UFSC }\end{array}$ & $\begin{array}{l}\text { Florianópolis, } \\
\text { SC }\end{array}$ & $\begin{array}{l}\text { Alunos da } \\
\text { Graduação e Pós- } \\
\text { Graduação da } \\
\text { UFSC e de outras } \\
\text { universidades }\end{array}$ & $18-30$ & 36 \\
\hline $18 / 10$ & $\begin{array}{l}17^{a} \text { Sepex (Semana de } \\
\text { Ensino, Pesquisa, } \\
\text { Extensão e Inovação) da } \\
\text { UFSC }\end{array}$ & $\begin{array}{l}\text { Florianópolis, } \\
\text { SC }\end{array}$ & $\begin{array}{l}\text { Alunos de } \\
\text { diversos cursos da } \\
\text { UFSC }\end{array}$ & $18-22$ & 20 \\
\hline $23 / 10$ & $\begin{array}{l}\text { IFSC Campus Pedra } \\
\text { Branca }\end{array}$ & Palhoça, SC & $\begin{array}{l}\text { Alunos da } \\
\text { Graduação em } \\
\text { Tecnologia em } \\
\text { Produção } \\
\text { Multimídia }\end{array}$ & $19-23$ & 26 \\
\hline $28 / 10$ & $\begin{array}{l}\text { Centro Educacional } \\
\text { Marista Lucia Mayvorne, } \\
\text { na Comunidade da } \\
\text { Serrinha }\end{array}$ & $\begin{array}{l}\text { Florianópolis, } \\
\text { SC }\end{array}$ & $\begin{array}{l}\text { Alunos do ensino } \\
\text { fundamental }\end{array}$ & $7-11$ & 20 \\
\hline $5 / 11$ & $\begin{array}{l}\text { Centro Educacional } \\
\text { Marista Lucia Mayvorne, } \\
\text { na Comunidade da } \\
\text { Serrinha }\end{array}$ & $\begin{array}{l}\text { Florianópolis, } \\
\text { SC }\end{array}$ & $\begin{array}{l}\text { Alunos das séries } \\
\text { finais do ensino } \\
\text { fundamental e do } \\
\text { ensino médio }\end{array}$ & $12-16$ & 20 \\
\hline
\end{tabular}

De acordo com o quadro acima pode-se observar cinco diferentes grupos de oficinas:

- Cinco oficinas em três comunidades de Florianópolis: duas na Casa da Criança do Morro da Penitenciária, divididas em quatro encontros com os grupos de crianças e adolescentes nos turnos da manhã e tarde; uma com crianças da Comunidade do Siri, no Bairro dos Ingleses; e duas junto ao Centro Educacional Marista Lúcia Mayvorne, da Comunidade da Serrinha, compostas por dois encontros cada uma, e dirigidas a crianças e adolescentes de faixas etárias diferentes.

- No Departamento de Jornalismo, foram quatro oficinas: três para as turma da disciplina de Laboratório em Fotojornalismo, sendo uma delas realizada durante a saída de estudos à Fortaleza de São José da Ponta Grossa, todas ministradas pela Professora Flávia Garcia 
Guidotti; e uma oficina ministrada pelo doutorando e voluntário Sílvio da Costa Pereira, sobre captação de imagens em 360 graus e Realidade Virtual junto à disciplina Estudos Avançados em Gêneros e Formatos, do Programa de Pós-Graduação em Jornalismo, sob responsabilidade da Professora Raquel Ritter Longhi;

- Em eventos internos da UFSC, foram duas oficinas, ambas realizadas no dia 18 de outubro de 2018: uma durante a I Jornada de Inovação no Jornalismo/JIJ, tendo à frente a Professora Raquel RitterLonghi e o doutorando Sílvio da Costa Pereira, e a outra no âmbito da Sepex, coordenada pela Professora Flávia Garcia Guidotti junto com os bolsistas Lívia Tokasiki e Felipe Buzzi;

- Em eventos externos foram ministradas duas oficinas, uma no $41^{\circ}$ Intercom, realizado em Joinville e outra durante o I Encontro Norte e Nordeste da ABCiber - Associação Brasileira de Pesquisadores em Ciberjornalismo, em São Luís do Maranhão, ministrada pela coordenadora do Projeto, Professora Raquel Ritter Longhi.

- Também foi oferecida uma oficina aos alunos da Graduação em Tecnologia em Produção Multimídiado IFSC, Campus Pedra Branca, emPalhoça, essa ministrada pelo doutorando Sílvio da Costa Pereira.

A seguir, apresentamos relatos mais detalhados das atividades que foram desenvolvidas junto às comunidades periféricas. Optamos por priorizar as mesmas, pois acreditamos que nelas o trabalho possuiu um caráter mais experimental e causou um maior impacto, já que grande parte dos participantes dessas oficinais estavam tendo o primeiro contato com a tecnologia de captação em 360 graus. Os relatos estão agrupados por localidade.

\section{Casa da Criança do Morro da Penitenciária}

As oficinas da Casa da Criança aconteceram nos dias 07 e 14 de maio de 2018, nos períodos da manhã e da tarde. Foram mobilizados nove voluntários do projeto, incluindo bolsistas e coordenadoras, para duas turmas, uma com crianças de 7 a 12 anos e outra com adolescentes entre 13 e 16 anos. No primeiro encontro, os bolsistas ficaram encarregados de realizar uma apresentação breve sobre o uso da fotografia e seus diversos gêneros e formatos, enfatizando o uso do celular como equipamento fotográfico - sabíamos, previamente, por parte da instituição, que a maioria dos alunos tinha acesso ao celular e smartphone. Ainda levamos a eles os diversos equipamentos, desde a pinhole e as câmeras analógicas, até a DSLR e a GoPro.

Para não ficarmos apenas na teoria, propomos uma atividade com os equipamentos a fim de que os alunos colocassem em prática alguns conceitos de luz e enquadramento que 
havíamos apresentado. A proposta inicial era que os alunos fizessem retratos entre eles, no entanto, na empolgação da atividade (muitos nunca tinham tido contato com as câmeras profissionais), abrimos para uma brincadeira mais lúdica, onde cada grupo experimentou o que cada equipamento fornecia. No final, a GoPro foi a que mais encantou os adolescentes, por causa do seu tamanho reduzido e pelo comando de voz: "GoPro, tira uma foto!".

O segundo encontro na Casa da Criança foi na semana seguinte, dia 14, e desta vez apresentamos a fotografia 360 e os óculos de Realidade Virtual. Diferente do primeiro encontro, fomos direto para o pátio da instituição, onde sentamos em um círculo e apresentamos a eles a câmera 360 que utilizamos no projeto e os óculos. Foi uma conversa rápida sobre o uso da fotografia 360 graus e suas diferenças com a fotografia plana, tradicional. Ainda pensando no uso do celular, nos preocupamos em apresentar a eles alguns aplicativos gratuitos que fazem fotos em 360 graus e dispõem vídeos em RV.

Era a primeira vez em que muitos usavam os óculos de Realidade Virtual, então foi uma experiência bem marcante. A princípio lhes mostramos vídeos documentais e/ou jornalísticos, para que eles pudessem vivenciar a imersão propiciada pelos equipamentos, mas, a pedido deles, acabamos apresentandotambém vídeos de entretenimento, como os de montanhas russas em Realidade Virtual, filmes de terror, futebol, games etc. Muitos ficaram fascinados e curiosos com o funcionamento dos equipamentos.

A atividade proposta também foi bastante atrativa para as crianças e para os adolescentes. Como a fotografia 360 capta todo o ambiente ao redor dela, propusemos uma brincadeira para que os alunos pudessem experimentar esse novo formato. A ideia era fazer um passeio virtual dentro da instituição, indo com eles nos locais que costumavam frequentar, sala de aula, pátio, biblioteca. Um aluno ficava responsável em escolher o enquadramento, analisando a posição da câmera, o movimento em volta (para que ninguém batesseno equipamento no momento da captura) e a quantidade de luz disponível; outro era responsável pela captação via celular. Como todos apareciam na foto, a brincadeira era um "esconde-esconde". Assim que apertavam o temporizador, todos tinham que procurar um local para não aparecer na fotografia. O resultado pode ser visto no perfil do Fotolivre360 na rede social Facebook. ${ }^{3}$

No geral, a experiência na Casa da Criança nos trouxe ensinamentos que levamos para as oficinas seguintes. Muitos conceitos prévios foram reformulados, como o de achar que as crianças teriam um conhecimento nulo sobre a ferramenta. Na verdade, para a nossa surpresa, o contato com a 360 não estava tão distante, sendo as redes sociais e também o YouTube duas plataformas onde algumas já haviam experimentado a realidade aumentada antes da oficina.

${ }^{3}$ https://www.facebook.com/fotolivreufsc360/?notif_id=1546454965340752\&amp;notif_t=page_fan. 
Também notamos que, em se tratando de crianças, uma abordagem mais lúdica acaba sendo ainda mais didática do que as referências teóricas, ainda que não se aprofunde muito sobre a fotografia em 360 graus. Seguindo nessa linha mais lúdica, levamos uma parte dessa experiência para as crianças da Comunidade do Siri, onde tivemos um retorno significativo da importância do projeto, tanto no sentido de divulgar a tecnologia, como no sentido de aproximar o público da fotografia.

\section{Comunidade do Siri}

No dia 24 de junho, realizamos a primeira oficina na comunidade do Siri, no bairro Ingleses, em Florianópolis. O contato com o líder comunitário foi feito pelo intermédio de dois voluntários que já haviam realizado projetos dentro da comunidade. Organizamos previamente o local da atividade - que aconteceu em uma creche no bairro -, como seria organizada, qual era o público, quais equipamentos levaríamos e o que seria apresentado. A proposta inicial, portanto, foi seguir com a mesma apresentação realizada na Casa da Criança do Morro da Penitenciária para, em seguida, realizarmos atividades práticas com os equipamentos de fotografia em 360 . No entanto, acabamos tendo que improvisar o formato da oficina justamente por ser um público mais jovem e disperso do que o anterior.

A oficina ocorreu em uma tarde de domingo, com um grupo de crianças entre 7 e 12 anos de idade. Optamos, na hora, por pular a apresentação teórica sobre a fotografia e irmos direto para a atividade prática, muito mais lúdica, até para conseguirmos captar mais a atenção das crianças. Apresentamos o projeto numa roda de conversas e permitimos que as crianças se apresentassem, contando um pouco da sua experiência com a fotografia. Diferente dos adolescentes da Casa da Criança, ali poucos tinham smartphones e o contato com a fotografia, na maioria das vezes, era por intermédio dos pais. Em seguida, apresentamos os equipamentos de fotografia, GoPro, DSLR, a Ricoh Theta 360 e os óculos de Realidade Virtual, que logo atraíram a atenção deles. Mostramos os efeitos que a câmera 360 causa na fotografia, o funcionamento dos equipamentos de captação e visualização e as diferenças com relação à fotografia plana, tradicional.

Observando o interesse das crianças em brincar com os equipamentos, improvisamos outra brincadeira, semelhante à que fizemos na Casa da Criança, porém dessa vez, a proposta era dividir as funções entre uma dupla, onde um seria o diretor de fotografia e o outro cinegrafista. A criança responsável em dirigir a cena decidia o que seria filmado e por onde o cinegrafista deveria passar. Depois os papéis eram invertidos. 
Observamos que a fotografia 360, ao contrário da fotografia tradicional, pode ser trabalhada em grupo, justamente pela sua ampla capacidade de captação do ambiente. $\mathrm{O}$ enquadramento e a mensagem a ser transmitida não fica limitada apenas ao olhar individual de um fotógrafo, que vai captar o quadro de acordo com o que vê. O uso do celular como display e do equipamento fotográfico conectado à Wi-Fi, possibilita uma colaboração maior entre duas ou mais pessoas.

Enquanto alguns produziam vídeos e fotos com os equipamentos disponíveis, outros usavam os óculos de Realidade Virtual pela primeira vez. A reação ao ver uma novidade tecnológica foi muito semelhante à dos adolescentes da Casa da Criança, pois os sentimentos de curiosidade e diversão são muito comuns. No entanto, na Comunidade do Siri, reparamos um potencial de interação e comunicação que os óculos podem propiciar. Observamos que uma das crianças, extremamente tímida e envergonhada em participar das atividades, ao ter contato com os óculos pela primeira vez, conseguiu interagir com as outras e se desprendeu totalmente da timidez, participando de todas as atividades propostas. Foi um retorno significativo e gratificante, principalmente se levarmos em conta a capacidade de inclusão digital e social que o projeto propiciou.

\section{Centro Educacional Marista Lúcia Mayvorne}

No Centro Educacional Marista Lúcia Mayvorne foram realizadas duas oficinas, uma pela manhã e outra à tarde, em duas semanas consecutivas. No dia 28 de outubro de 2018, deu-se o primeiro encontro, com crianças de sete a onze anos que produzem um pequeno jornal comunitário dentro da Escola. Com a presença do bolsista Felipe Buzzi e da vice-coordenadora Flávia Guidotti, a oficina teve início com uma conversa com os participantes, que se apresentaram e contaram experiências que já teriam tido com fotografia.

Num segundo momento, foi feita uma breve apresentação sobre a fotografia e as diversas linguagens e formatos. Logo após, saímos para um parque ambiental próximo à escola, o Parque Municipal do Morro da Cruz, acompanhados de uma professora da escola. No local, os alunos puderam colocar em prática alguns conceitos apresentados, além de pensarem em possíveis pautas ambientais que pudessem ser registradas usando a fotografia. Fizemos um passeio dentro do parque, onde as crianças tiraram diversas fotografias denunciando a situação do local, além de contarem a história dele e destacarem a importância de preservar o parque para a comunidade. 
$\mathrm{Na}$ tarde do mesmo dia, reunimos uma turma composta por um grupo de adolescentes, entre 12 e 16 anos, interessados em fotografia, sendo que uma parte deles já havia mantido contato com a mídia. A apresentação inicial foi mais teórica, trazendo referências importantes e questões mais técnicas pensadas para que eles pudessem executar em suas tarefas cotidianas. Conversamos sobre alguns aspectos do fotojornalismo, trouxemos fotógrafos e sites para que os alunos pudessem pesquisar referências interessantes e demos dicas sobre programas e aplicativos. A atividade foi realizada com uma câmera GoPro e com o uso dos celulares. Os alunos puderam então pôr em prática alguns conceitos que apresentamos e dispuseram-se a fotografar pontos importantes da história e/ou do cotidiano daquela comunidade. Sentimosque com as atividades conseguimos despertar ainda mais o interesse deles pela fotografia e pelo fotojornalismo.

A segunda oficina realizada junto ao Centro Educacional Marista Lucia Mayvorne ocorreu dia 05 de novembro de 2018, nos dois turnos. Na parte da manhã, o bolsista Felipe Buzzi e as coordenadoras Raquel Ritter Longhi e Flávia Garcia Guidotti fizeram uma atividade mais lúdica para apresentar a fotografia 360 e os óculos de Realidade Virtual, uma vez que aquela turma era composta por crianças de 7 a 11 anos. O espaço reservado para esse encontro foi um laboratório onde os alunos produzem um pequeno jornal comunitário. Aliforam feitas as primeiras apresentações e conversas sobre as experiênciasdo primeiro encontro.

Na parte da tarde, com a presença da bolsista Lívia Tokasiki, das coordenadoras Raquel Ritter Longhi e Flavia Garcia Guidotti e do voluntário Rodrigo Barbosa, a reunião foi no auditório, já com a segunda turma de adolescentes. Primeiramente foi feita uma apresentação para introduzir o projeto e a fotografia em 360 graus. Logo de início, foi possível perceber que a turma já tinha conhecimentos a respeito da fotografia em geral e alguns alunos até já haviam experimentado registros em realidade aumentada, mas esses eram minoria. Por isso, o segundo momento foi reservado para experimentação dos óculos de Realidade Virtual, quandoos jovens puderam ter um contato mais imersivo das imagens em 360.

Por fim realizamos uma série de fotografias e vídeos com duas câmeras Ricoh Theta, abrangendo o espaço da instituição e também do Parque Natural Municipal do Morro da Cruz. No local, todas as crianças puderam experimentar de maneira criativa a fotografia em $360^{\circ}$ e os óculos de Realidade Virtual.

\section{CONSIDERAÇÕES FINAIS}

Do ponto de vista dos objetivos propostos e resultados esperados, podemos afirmar que as metas foram alcançadas. O projeto tinha como principal objetivo fortalecer a inclusão social, 
através da prática da produção de imagens fotográficas e em vídeo em 360 graus no intercâmbio entre a comunidade universitária e comunidades periféricas, com a participação de alunos do Curso de Jornalismo da UFSC. Entendemos que esse objetivo foi alcançado, especialmente pela grande participação dos grupos de oficineiros, como também pelo número de participantes nas oficinas e, por último, pelo engajamento do público em geral com as postagens nas redes sociais do projeto ${ }^{4}$.

Nascido em um momento de profusão de imagens fotográficas em redes sociais, entendemos que o Fotolivre 360 cumpriu também o seu papel de vetor para a reflexão sobre o tipo de imagens que circulam na Internet e, principalmente, sobre o poder da rede não só para a disseminação dessas imagens, mas também como veículo capaz de dar voz aos cidadãos, tornando-os sujeitos de suas próprias histórias. Nesse sentido, acreditamos que as oficinas e as saídas fotográficas que foram realizadas fizeram com que os sujeitos participantes pudessem agir como atores sociais e documentaristas de suas próprias realidades, e que, a partir dessas experiências, possam atuar como transformadores sociais.

Quanto aos nossos alunos, acreditamos que eles também aprenderam muito com essasvivências, uma vez que o olhar atento para diferentes comunidades pode promover a redução das distâncias entre essas duas realidades por vezes tão distintas, ou seja, o mundo acadêmico universitário e as comunidades periféricas e os projetos sociais voltados para jovens de classes populares.

De uma perspectiva comparativa entre esses dois âmbitos em que as oficinas se deram, ou seja, o universitário e o extra-universitário (comunidades periféricas), podem ser registrados dois aspectos fundamentais: o primeiro diz respeito ao impacto das atividades sobre o público universitário e sobre os participantes de ambientes menos privilegiados do ponto de vista, dentre outros, das oportunidades de acesso a tecnologias de captação de imagens. No âmbito da Universidade, notamos o estímulo à pesquisa e produção com tecnologias de captação de imagens em 360 graus, dentro do contexto de novas tecnologias e usos das imagens no jornalismo, além de formação de professores de outras universidades. Neste caso, tanto doutorandos e mestrandos do Programa de Pós-Graduação em Jornalismo, como externos, participantes e também ministrantes de oficinas. Pesquisadores e profissionais que se empenharam no estudo mais aprofundado de tais tecnologias e seus efeitos sobre a prática jornalística, como é o caso do Professor Sílvio da Costa Pereira, à época doutorando do PPGJOR e professor da Universidade Federal do Mato Grosso do Sul, que ministrou duas oficinas na

\footnotetext{
${ }^{4} \mathrm{O}$ perfil na rede social Facebook agregou imagens oriundas das oficinas junto à comunidade universitária e comunidade em geral, totalizando, no período, 24 publicações, incluindo 67 fotos e 5 vídeos. O projeto também teve um perfil na rede Instagram, como 12 publicações.
} 
UFSC, em parceria com a coordenadora do projeto. Após sua defesa, em 2019, o professor retomou seu trabalho de docência junto à sua Universidade, desenvolvendo pesquisa e orientações de pesquisa que possuem como objeto as tecnologias de imagem.

Sobre o impacto dessas atividades junto ao público externo, as comunidades, observamos que a tarefa das professoras coordenadoras e dos bolsistas de levar esse tipo de conhecimento e prática proporcionou um aprendizado recíproco. Isso porque, muitas vezes, aprendemos a ver com os olhos dos participantes, e conseguimos entender, desta forma, um pouco mais de suas realidades sociais. Além de reforçar a inclusão digital, através do uso de equipamentos, vimos ainda, florescer a criatividade entre alguns jovens oficineiros, como na oficina realizada junto à comunidade do Siri. Naquele domingo, o menino Jorge, de oito anos, fez uso da câmera de 360 graus com o apoio do suporte (stick) e gravou um "passeio" sobre um brinquedo tubular da pracinha da creche, produzindo imagens circulares surpreendentes e inovativas. Um outro momento notável, e já citado anteriormente, se deu na mesma oficina, quando percebemos uma das participantes, uma menina de seus 7 anos, que chegou muito tímida e calada, e que parecia ter dificuldades de se relacionar com o grupo. Ao longo da oficina, e entrando em contato com a prática do uso de óculos de Realidade Virtual, a criança tornou-se mais participativa. Ao final da oficina, era uma criança diferente daquela menina triste que vimos chegar junto ao grupo.

O projeto foi um importante espaço agregador do tripé que sustenta as universidades públicas brasileiras, ou seja, o ensino, a pesquisa e a extensão, uma vez que serviu de base para muitas discussões teóricas promovidas nas disciplinas de Fotojornalismo,da Graduação em Jornalismo, e deGêneros e Formatos Jornalísticos, da Pós-Graduação em Jornalismo. Além disso, o projeto também foi divulgado em eventos científicos, como a Intercom Sul e o Encontro da ABCiber.

Finalizado, o Projeto Fotolivre360 cumpriu com seus propósitos principais, ao mesmo tempo em que se coloca como modelo de projeto de extensão capaz de agregar a comunidade acadêmica e a comunidade em geral.Acreditamos que conseguimos utilizar a fotografia como ferramenta de inclusão social, de redução das distâncias e das diferenças e, consequentemente, da promoção do empoderamento mútuo. 


\section{REFERÊNCIAS}

BONI, Paulo César. O nascimento do fotodocumentarismo de denúncia social e seu uso como "meio" para transformações na sociedade. Anais do Intercom. Disponível em: http://www.intercom.org.br/papers/nacionais/2008/resumos/R3-0475-1.pdf. Acesso em: 20 mar. 2018.

FORIN JUNIOR, Renato; BONI, Paulo César. Aspectos valorativos no fotodocumentarismo social de Sebastião Salgado. Conexão. Caxias do Sul, v. 6, p. 71-95, 2007.

GURAN, Milton, O olhar engajado: inclusão visual e cidadania. Studium, Campinas, v. 27, 2008. Disponível em: http:// www.studium.iar.unicamp.br. Acesso em: 20 mar. 2009.

SOUSA, Jorge Pedro. Fotojornalismo: introdução à história, às técnicas e à linguagem da fotografia na imprensa. Florianópolis: Letras Contemporâneas, 2004.

Recebido em: 23/11/2019

Aceito em: 05/08/2020 